\title{
Evaluation and Simulation of the Microstructural Changes and Embrittlement in 21/4Cr-1Mo Steel due to Long Term Service
}

\author{
Sivakumaran WIGNARAJAH, 1) Isao MASUMOTO2) and Takashi HARA ${ }^{3)}$
}

1) IRI Laser Laboratory, Takada, Kashiwa, Chiba-ken, 277 Japan.

2) Faculty of Engineering, Nagoya University, Furo-cho, Chikusaku, Nagoya, Aichi-ken, 464-01 Japan.

3) Hitachi Works, Hitachi Ltd., Saiwai-cho, Hitachi, Ibaraki-ken, 317 Japan.

(Received on June 9, 1989; accepted in the final form on September 8, 1989)

\begin{abstract}
Study of the microstructural changes and the embrittlement behaviour of a $21 / 4 \mathrm{Cr}-1$ Mo steel with low impurity content by isothermal aging for periods of up to $10000 \mathrm{~h}$ at 823,873 and $898 \mathrm{~K}$ showed that although grain boundary segregation of phosphorus or other impurity elements were not recognized, considerable reduction in notch toughness occurred due to the microstructural changes associated with the precipitation and coarsening of carbides. It has been shown that the toughness degradation due to long term aging has a linear relationship with the parameter $T(\log t+8)$ where $T$ is the aging temperature and $t$, the aging time. It has also been suggested that step cooling alone is not a viable method of estimating long term embrittlement.

Using the above parameter, it ought to be possible to formulate a method by which the microstructural changes and toughness degradation occurring due to long term service of the order of $100000 \mathrm{~h}$ could be effectively simulated in the laboratory by heat treatment of a few thousand hours. An illustrative example of simulation of the changes in carbide morphologies, hardness and toughness that occurred in a $21 / 4 \mathrm{Cr}-1$ Mo steel due to $88000 \mathrm{~h}$ service at $813 \mathrm{~K}$ has been presented.
\end{abstract}

KEY WORDS: Cr-Mo steel; service embrittlement; step cooling; elevated temperature service; simulation of notch toughness; carbide morphologies.

\section{Introduction}

At present, many of the older electric power plants and petroleum plants built 10 or 20 years ago are approaching their design life expectancy and the assessment of the remaining operating life of such plant equipment is a common topic of research and discussion in these industries. Low alloy heat resisting $\mathrm{Cr}-$ Mo steels are used widely as the material for plant components operated at elevated temperatures, and assessement or prediction of the embrittlement occurring in Gr-Mo steels during long term elevated temperature service is also one of the important considerations in the determination of the serviceability or remanent life of such plant components.

In previous studies, ${ }^{1-3)}$ the authors have shown that long term service embrittlement in $\mathrm{Cr}-\mathrm{Mo}$ steels is dependant mainly on the microstructural changes associated with the precipitation and coarsening of carbides, together with the effect of grain boundary segregation of phosphorus, if any. Moreover, it was also suggested that phosphorus segregation is a relatively short term phenomenon which can be simulated by G. E. Step Cooling*, whereas carbide coarsening behaviour, which cannot be simulated by step cooling, becomes the more dominant cause of embrittlement when considering service periods of 10 or 20 years. Thus, step cooling has been shown to be incapable of simulating long service embrittlement. ${ }^{2-4)}$

In this study, the authors have attempted to find a method of simulating the microstructural changes and embrittlement occurring in a $2 \frac{1}{4} \mathrm{Cr}-1$ Mo steel due to long service by shorter term heat treatment. For this purpose, initial studies were conducted by systematically aging a special heat of $2 \frac{1}{4} \mathrm{Cr}-1 \mathrm{Mo}$ steel with low phosphorus content at 823 to $898 \mathrm{~K}$ for periods upto $10000 \mathrm{~h}$ in order to determine the effect of aging temperature and time on the microstructural changes - the carbide coarsening behaviour in particular, and to derive a relationship between the embrittlement and the aging conditions. These results are then made use of in the latter part of this paper to simulate, using "virgin" state steel, the microstructural changes and embrittlement that had been observed in a $2 \frac{1}{4} \mathrm{Gr}-1$ Mo steel after $88000 \mathrm{~h}$ service in a power station boiler header operated at $813 \mathrm{~K}$.

\section{Materials and Experimental Details}

The chemical composition of the special heat of normalized and tempered $2 \frac{1}{4} \mathrm{Cr}-1$ Mo steel (Steel A) used in the first part of this study is shown in Table 1. The phosphorus content of the steel is very low $(0.005 \%)$ and, in addition, its silicon content is also low. Aging was carried out mainly at 823 and 873 $\mathrm{K}$ for periods ranging upto $10000 \mathrm{~h}$. A limited num-

* G. E. Step Cooling: An accelerated embrittling treatment often used to estimate the service embrittlement of Cr-Mo steels, comprising the following stepwise heat treatment: $866 \mathrm{~K} \times 1 \mathrm{~h}-811 \mathrm{~K} \times 15 \mathrm{~h}-796 \mathrm{~K} \times 24 \mathrm{~h}-768 \mathrm{~K} \times 60 \mathrm{~h}-741 \mathrm{~K} \times 125 \mathrm{~h}-623 \mathrm{~K}$ (cooling rate: $2.8 \mathrm{~K} / \mathrm{min}$ )-A.C. 
Table I. Chemical composition of Steel A. (wt\%)

\begin{tabular}{ccccccccc}
\hline Material & $\mathrm{C}$ & $\mathrm{Si}$ & $\mathrm{Mn}$ & $\mathrm{P}$ & $\mathrm{S}$ & $\mathrm{Cr}$ & Mo & Heat treatment \\
\hline Steel A $(2 \mathrm{~K} \mathrm{Cr}-1 \mathrm{Mo})$ & 0.14 & 0.12 & 0.52 & 0.005 & 0.002 & 2.46 & 1.03 & $\begin{array}{c}1213 \mathrm{~K} \times 45 \mathrm{~min}, \text { A. C., } \\
973 \mathrm{~K} \times 45 \mathrm{~min}, \mathrm{~A} . \mathrm{C} .\end{array}$ \\
\hline
\end{tabular}

ber of specimens were aged at $898 \mathrm{~K}$. In addition, one set of specimens were subjected to G.E. Step Cooling.

Charpy impact tests were performed using full size specimens (JIS Z 2202, No. 4) and the embrittlement was assessed by determining the increase ( $\triangle \mathrm{FATT}$ ) in the fracture appearance transition temperature. Optical microscopy and transmission electron microscopy using carbon extraction replicas were carried out to determine the microstructural changes. Carbide sizes were measured from transmission electron micrographs taken at 10000 magnification, using an image analysing computer program. At least 1000 carbides were measured from each specimen and the mean carbide sizes were determined. Grain boundary segregation of phosphorus was assessed by the etching method proposed by Ogura et al. ${ }^{5}$ ) who have shown that the etched depth of the grain boundary is proportional to the grain boundary concentration of phosphorus.

\section{Results and Discussion}

\subsection{Optical Microstructure}

In the as normalized and tempered condition, steel A had a tempered bainitic microstructure (Fig. 1(a)) and the average Vickers hardness measured with a $10 \mathrm{~kg}$ load was 205 . The grain size corresponded approximately to ASTM grain size No. 7. After $500 \mathrm{~h}$ aging at $823 \mathrm{~K}$, the hardness decreased slightly to 203, but, as shown in Fig. 1(b), no major change in the optical microstructure was visible. As the holding time became longer, the bainitic microstructure gradually degenerated into ferrite and carbide, and an apparent increase in the interparticle distances was noticeable as in Fig. 1(c) which shows the microstructure after $10000 \mathrm{~h}$ at $823 \mathrm{~K}$. The trend was similar at $873 \mathrm{~K}$, but faster than at $823 \mathrm{~K}$. Fig. 1(d) shows the microstructure after $10000 \mathrm{~h}$ at $873 \mathrm{~K}$. The hardness after $10000 \mathrm{~h}$ at $873 \mathrm{~K}$ was 164 compared to 183 after the same aging period at $823 \mathrm{~K}$.

\subsection{Identification of Precipitates}

Identification of the precipitates by X-ray diffraction of residues obtained through electrolysis showed that $\mathrm{M}_{3} \mathrm{C}$ and $\mathrm{M}_{7} \mathrm{C}_{3}$ type carbides were predominant in the as normalized and tempered condition. Weaker diffraction peaks indicating $\mathrm{M}_{23} \mathrm{C}_{6}$ and $\mathrm{M}_{2} \mathrm{C}$ type carbides were also observed. With increasing holding time at $873 \mathrm{~K}$, the tendency was for $\mathrm{M}_{3} \mathrm{G}$ type and $\mathrm{M}_{2} \mathrm{G}$ type carbides to gradually decrease and for $\mathrm{M}_{23} \mathrm{C}_{6}$ and $\mathrm{M}_{6} \mathrm{C}$ type carbides to be precipitated increasingly. The same trend was noticed at $823 \mathrm{~K}$ but occurred at a slower rate.
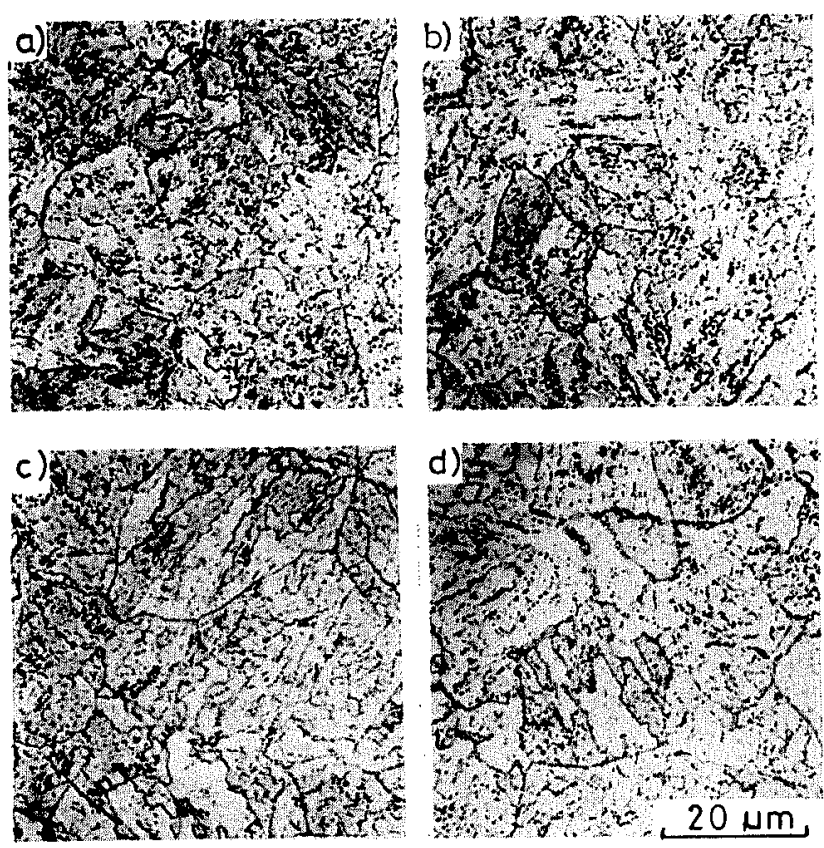

(a) As normalized and tempered

(b) After $823 \mathrm{~K} \times 500 \mathrm{~h}$

(c) After $823 \mathrm{~K} \times 10000 \mathrm{~h}$

(d) After $873 \mathrm{~K} \times 10000 \mathrm{~h}$

Fig. 1. Optical micrographs showing the effect of aging time and temperature on the microstructure of Steel A (Picral etch).

\subsection{Grain Boundary Segregation of Phosphorus}

The presence of grain boundary segregation of phosphorus, a commonly mentioned cause of embrittlement in Gr-Mo steels, was checked by measuring the grain boundary etched depth after etching with a picric acid etchant for $2 \mathrm{~h}$. The grain boundary etched depth has been shown to be directly related to the amount of grain boundary phosphorus segregation. ${ }^{5)}$ The results are shown in Fig. 2 and it is evident that the grain boundary etched depth is not increased significantly either by isothermal aging, or by step cooling. It can thus be concluded that no significant grain boundary segregation of phosphorus occurred in this heat of $2 \frac{1}{4} \mathrm{Cr}-1 \mathrm{Mo}$ steel during isothermal aging upto $10000 \mathrm{~h}$ or during step cooling.

\subsection{Transmission Electron Microscopy and Particle Size Measurement}

The changes in the morphology and distribution of carbides were studied by transmission electron microscopy of carbon extraction replicas. Fig. 3 illustrates typical examples. In the as normalized and tempered condition, a distribution of very fine acicular carbides and larger rod like or spherical carbides were present (Fig. 3(a)). The fine acicular carbides were identified as $\mathrm{M}_{2} \mathrm{C}$ type by selected area electron dif- 


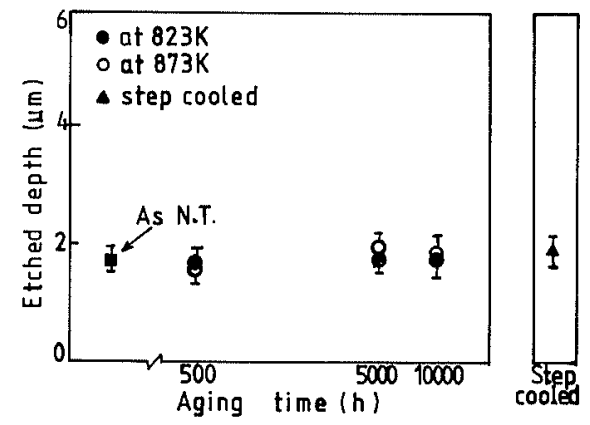

Fig. 2. Grain boundary phosphorus segregation in Steel A evaluated by the grain boundary etching method, indicating that no significant segregation has occurred in this steel due to isothermal holding or step cooling.
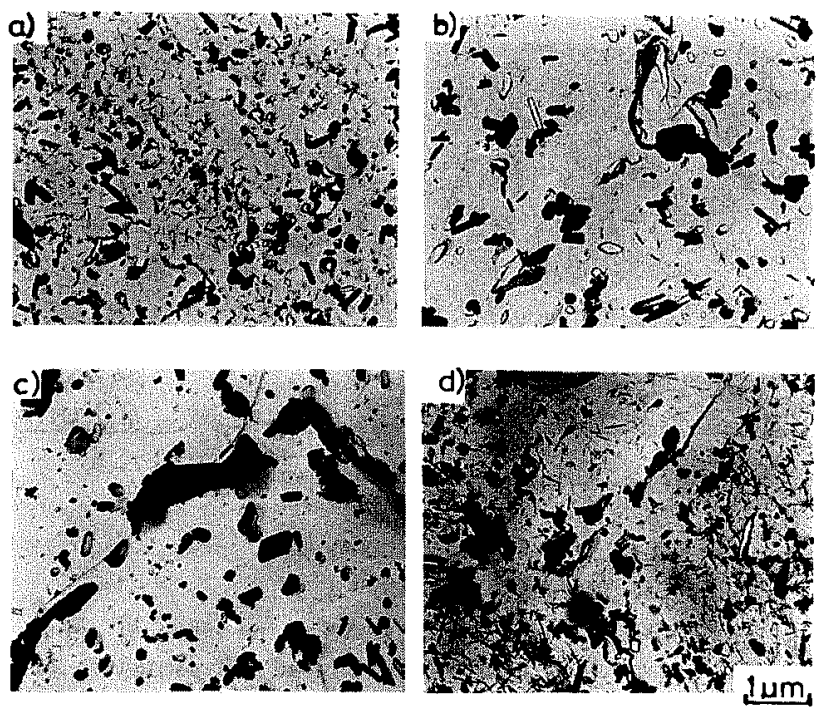

(a) As normalized and tempered

(b) After $873 \mathrm{~K} \times 5000 \mathrm{~h}$

(c) After $873 \mathrm{~K} \times 10000 \mathrm{~h}$

(d) After $823 \mathrm{~K} \times 5000 \mathrm{~h}$

Fig. 3. Effect of aging time and temperature on the carbide morphologies of Steel A.

fraction. Step cooling did not produce any major change in the carbide morphology and distribution. After $5000 \mathrm{~h}$ at $873 \mathrm{~K}$, almost all of the fine $\mathrm{M}_{2} \mathrm{C}$ type carbides that were present in the as normalized and tempered condition had disappeared and coarse blocky carbides were precipitated (Fig. 3(b)). Further coarsening occurred when the holding time was increased to $10000 \mathrm{~h}$ with long, thick carbide films being formed along the grain boundaries as illustrated in Fig. 3(c). At $823 \mathrm{~K}$, the carbide morphology changes were slower as is evident by comparing Fig. 3(d) with Fig. 3(b). The carbides are smaller and the fine $\mathrm{M}_{2} \mathrm{C}$ carbides which had disappeared after $5000 \mathrm{~h}$ at $873 \mathrm{~K}$ are still present after the same aging time at $823 \mathrm{~K}$.

Fig. 4 shows the change in mean carbide sizes as a function of holding time at 823 and $873 \mathrm{~K}$. Because of the large scatter in the results, there is no clear difference in the mean carbide sizes at $0 \mathrm{~h}$ (as normalized and tempered) and $500 \mathrm{~h}$. However, at longer aging times $(5000 \mathrm{~h}$ and $10000 \mathrm{~h})$, the mean carbide size

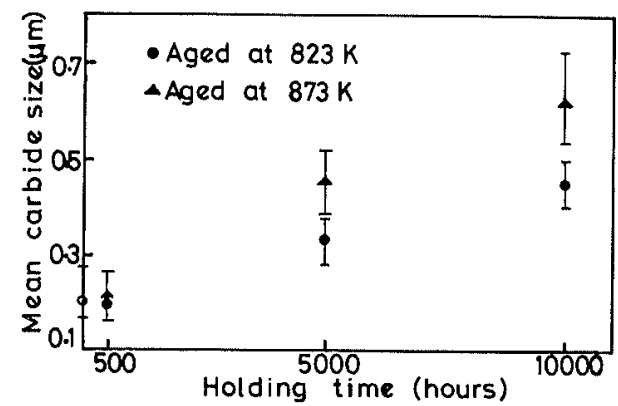

Fig. 4. Mean carbide sizes in Steel $\mathrm{A}$ as a function of aging time and temperature.

can be seen to increase gradually, and the coarsening rate is evidently faster at $873 \mathrm{~K}$ than at $823 \mathrm{~K}$.

\subsection{Charpy Impact Testing and Fracture Surface Exami- nation}

In the normalized and tempered condition, the fracture appearance transition temperature (FATT) of steel A was $174 \mathrm{~K}$ and the upper shelf energy was $30.0 \mathrm{~kg} \cdot \mathrm{m}$. The change in notch toughness due to step cooling and isothermal aging, expressed by the increase in FATT, is shown in Fig. 5. Step cooling produced almost no change in the FATT. During isothermal holding at $823 \mathrm{~K}$, there was no significant embrittlement in the first $1000 \mathrm{~h}$. At 873 and 898 $\mathrm{K}$, embrittlement occurred earlier and, for any given holding time, was larger than at $823 \mathrm{~K}$. It was found that the long term embrittlement behaviour at the different temperatures could be expressed by the parameter

$$
T(\log t+C)
$$

where, $C:$ a constant

$T$ : the holding temperature $(\mathrm{K})$

$t:$ the holding time $(\mathrm{h})$.

In the present case, best correlation was obtained when $C$ took the value 8 as illustrated in Fig. 6 , and the change in FATT can be represented by an equation of the following form:

$$
\Delta \mathrm{FATT}=A \cdot T(\log t+8)+B
$$

where, $A, B:$ a constants.

The parameter $T(\log t+C)$ was proposed by Larson and Miller in 1952, $\left.{ }^{6}\right)$ and is based on the rate process theory which states that the rate at which a certain process progresses is related to the temperature $(T)$ and time $(t)$ by the following equation ${ }^{6)}$ :

$$
1 / t=K \cdot \exp (-Q / R T)
$$

where, $1 / t:$ the rate

$K:$ a constant

$Q:$ the activation energy for the process

$R$ : the gas constant.

Eq. (2) can be reduced to the following form:

$$
T(\log t+C)=Q / 2.3 R=\text { const. }
$$

The left hand side of Eq. (3) is now well known as the Larson-Miller parameter (or tempering parameter). It is believed to express the carbide transforma- 
tion and growth rates in Gr-Mo steel at elevated temperatures, and the resulting mechanical property changes. The value of the constant $C$ would be dependant on several factors such as the chemical composition of the steel, its initial microstructure, grain size, etc. Although the values most commonly attributed to $C$ seem to be 17-20 when carbide precipitation sequences ${ }^{7)}$ or mechanical property changes ${ }^{8-10)}$ in $\mathrm{Cr}-\mathrm{Mo}$ steels due to aging at different temperatures are investigated, it is interesting to note that in at least one investigation, ${ }^{11}$ ) a value of 8 has been found to be more appropriate for expressing the carbide precipitation behaviour in $\mathrm{Cr}-$ Mo steels. In the present case, the large scatter in the carbide size measurements prevent any definite conclusion being reached regarding the most appropriate value of $C$ for expressing the carbide sizes. However, when the carbide sizes were plotted against the parameter $T(\log t+C)$, a somewhat better correlation was obtained when $C=8$ was used rather than when the more common value of $C=20$ was used.

Examination of the brittle fracture surfaces after

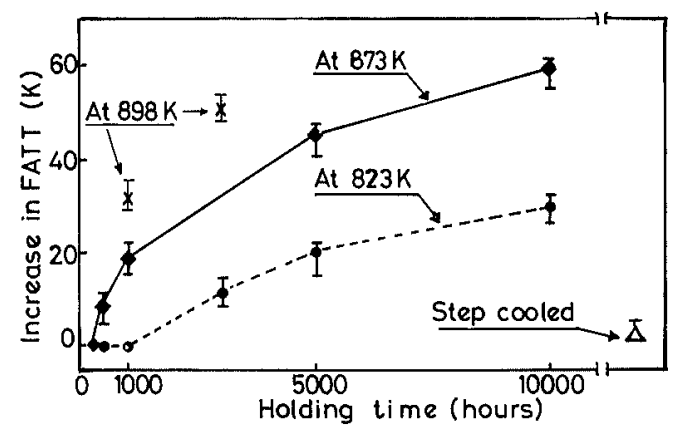

Fig. 5. Effect of isothermal aging (at 823, 873, $898 \mathrm{~K}$ ) and step cooling on the increase in fracture appearance transition temperature (FATT) of Steel A.

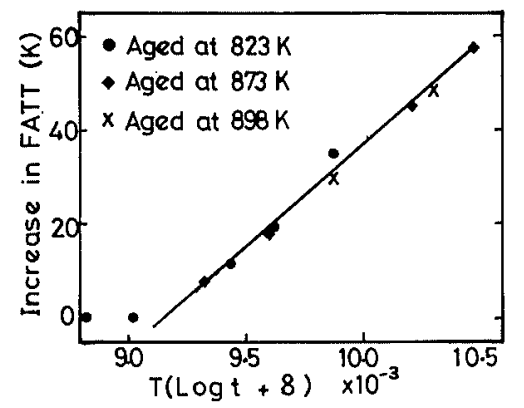

Fig. 6. Increase in FATT of Steel A plotted as a function of the parameter $T(\log t+8)$, where $T$ is the aging temperature and $t$, the aging time. impact tests by scanning electron microscope showed transgranular cleavage to be the brittle fracture mode in the as normalized and tempered condition and at short aging times. In the case of aging times of $5000 \mathrm{~h}$ or more, the brittle fracture mode was still mainly transgranular, but a small amount of intergranular fracture facets (accounting for about 3-8\% of the total fracture area) were noticed as shown in Fig. 7(a). Since there was a possibility that such intergranular fracture was due to impurity element segregation other than phosphorus, analysis of the transgranular and intergranular fracture surfaces was carried out by energy dispersive X-ray analysis (EDX), but no segregation of sulphur, tin, arsenic, antimony, or phosphorus could be determined. (Admittedly, EDX analysis is not as reliable as Auger analysis for detecting intergranular segregation. Although initial attempts were made to check grain boundary segregation by Auger analysis, they proved to be inconclusive because, unlike in the Charpy specimens, it was not possible to locate intergranular facets in the notched circular Auger specimens fractured at low temperature in situ in the Auger apparatus). In the absence of any conclusive evidence of grain boundary segregation, it is believed that the intergranular fracture observed may have been caused by the weakening of grain boundary cohesion resulting from coarsening of grain boundary carbides. The high magnification view (Fig. 7(b)) shows evidence of carbides remaining on the intergranular facet after fracture, and a sub-crack propagating along the carbide/grain boundary interfaces is also visible.

Fig. 8 is a plot of the change in FATT against the mean carbide size. Although it is difficult to establish a definite mathematical relationship between the carbide size and change of FATT because of the scatter in the carbide size measurements, it is clear that, within the range of the experiment, the overall

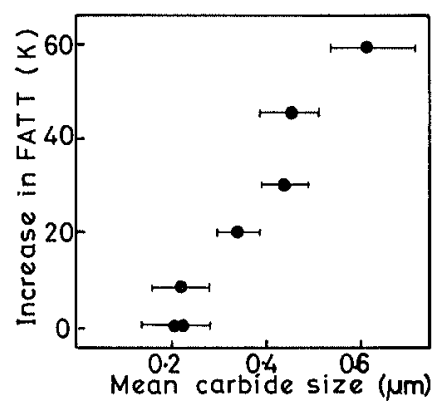

Fig. 8. Relationship between increase in FATT and mean carbide size.
Fig. 7.

(a) SEM micrographs of the fracture surfaces of Steel $\mathrm{A}$ aged at $823 \mathrm{~K}$ for $5000 \mathrm{~h}$, indicating the presence of intergranular fracture facets.

(b) A high magnification view of the intergranular facet, indicating the presence of carbide particles.
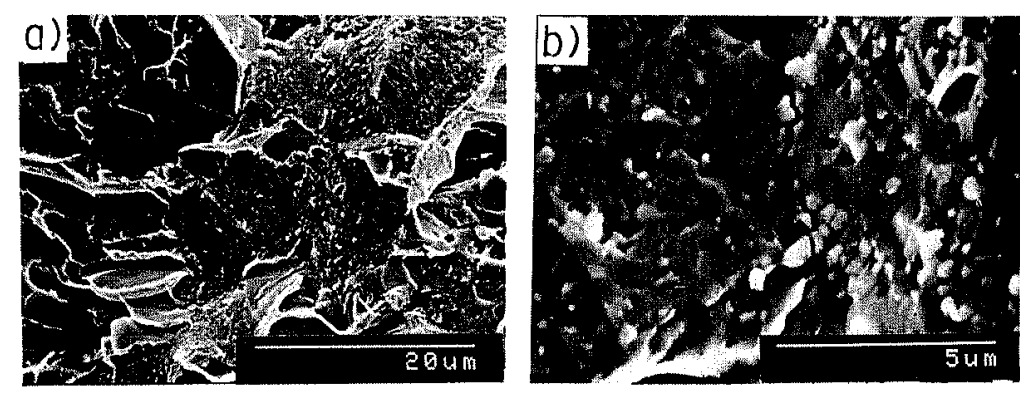
tendency is for the embrittlement to increase with increasing carbide size. It is also clear from the results that even in the absence of impurity segregation, considerable embrittlement can occur in $2 \frac{1}{4} \mathrm{Gr}-1 \mathrm{Mo}$ steel in the long term due to carbide coarsening. Although step cooling is often used to estimate the susceptibility to service embrittlement, it is obvious that it cannot simulate long term embrittlement because the carbide morphologies are not significantly changed by this embrittling treatment.

\section{Microstructural Comparison with a Service Exposed Steel}

Fig. 9 compares previously reported ${ }^{2)}$ carbide morphologies in a $2 \frac{1}{4} \mathrm{Gr}-1$ Mo steel B (whose chemical composition is shown in Table 2) after service at $813 \mathrm{~K}$ for $88000 \mathrm{~h}$, with those of Steel A aged for $10000 \mathrm{~h}$ at $873 \mathrm{~K}$. The phosphorus content of the service exposed steel $\mathrm{B}(0.02 \%)$ is considerably higher than that of Steel A $(0.005 \%)$. Furthermore, the initial normalizing and tempering heat treatment conditions of the two steels were also different. Direct comparison is therefore not possible but there appears to be a close resemblance in the carbide morphologies and distribution in the service exposed steel B and those of steel A aged for $10000 \mathrm{~h}$ at $873 \mathrm{~K}$. In fact, calculation shows that the parameter $T(\log t$ $+8)$ is,

$$
\begin{aligned}
& =10467 \text { for } 10000 \mathrm{~h} \text { at } 873 \mathrm{~K} \text {, and } \\
& =10524 \text { for } 88000 \mathrm{~h} \text { at } 813 \mathrm{~K} .
\end{aligned}
$$

These two values of $T(\log t+8)$ being nearly equal, the above indicates that there is a possibility of simulating the microstructural changes associated with the precipitation and coarsening of carbides during long service and the resulting embrittlement, by aging for shorter periods at higher temperatures calculated using the parameter $T(\log t+8)$. This possibility

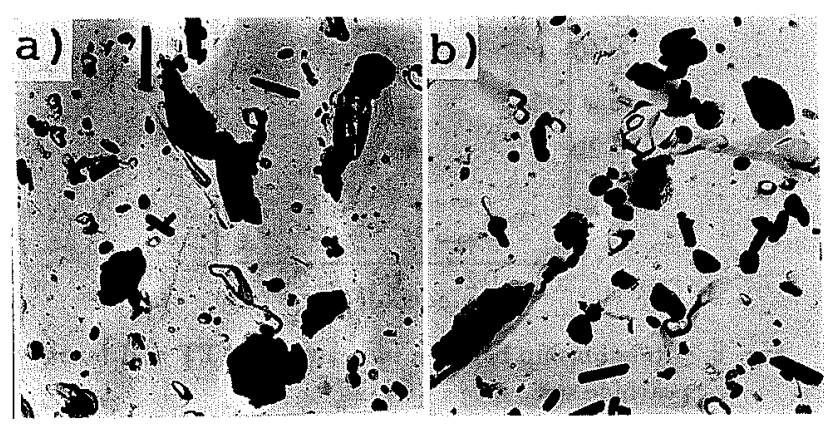

(a) Steel B, as service exposed $(813 \mathrm{~K} \times 88000 \mathrm{~h})$

(b) Steel A, after $873 \mathrm{~K} \times 10000 \mathrm{~h}$

Fig. 9. Carbide morphologies of the service exposed steel (Steel B) compared to those of Steel A aged at 873 $\mathrm{K}$ for $10000 \mathrm{~h}$. was verified in the following manner:

The service exposed steel B was first subjected to solution treatment followed by normalizing and tempering (1 $473 \mathrm{~K} \times 1 \mathrm{~h}, \mathrm{~W} . \mathrm{Q} .+1213 \mathrm{~K} \times 2 \mathrm{~h}, \mathrm{~A} . \mathrm{C}$., 973 $\mathrm{K} \times 2 \mathrm{~h}, \mathrm{~A} . \mathrm{C}$.). It has been made clear in a previous study ${ }^{2}$ that this treatment reverses the microstructural changes that occurred during long service and completely restores the notch toughness of the service exposed steel to the same level as that of virgin steel. From this "virgin state", the steel was aged for $5240 \mathrm{~h}$ at $898 \mathrm{~K}$, which is the calculated equivalent of the service exposure conditions of $88000 \mathrm{~h}$ at 813 K. After this aging treatment, which was intended to simulate the microstructural changes associated with carbide precipitation and coarsening during service, the steel was subjected to G.E. Step Cooling to promote grain boundary phosphorus segregation. (It has been shown in the earlier study ${ }^{2)}$ that the embrittlement observed in the service exposed steel was due to the combined effects of carbide coarsening and grain boundary phosphorus segregation). Fig. 10 shows the Charpy impact test results of steel B in the service exposed state, "virgin" state and the service exposure simulated state. It can be seen that the simulation treatment of $898 \mathrm{~K} \times 5240 \mathrm{~h}+$ step cooling applied to the "virgin" state steel has produced an embrittlement nearly identical to the embrittlement caused by actual long term service exposure. Hardness measurements indicated that the Vickers hard-

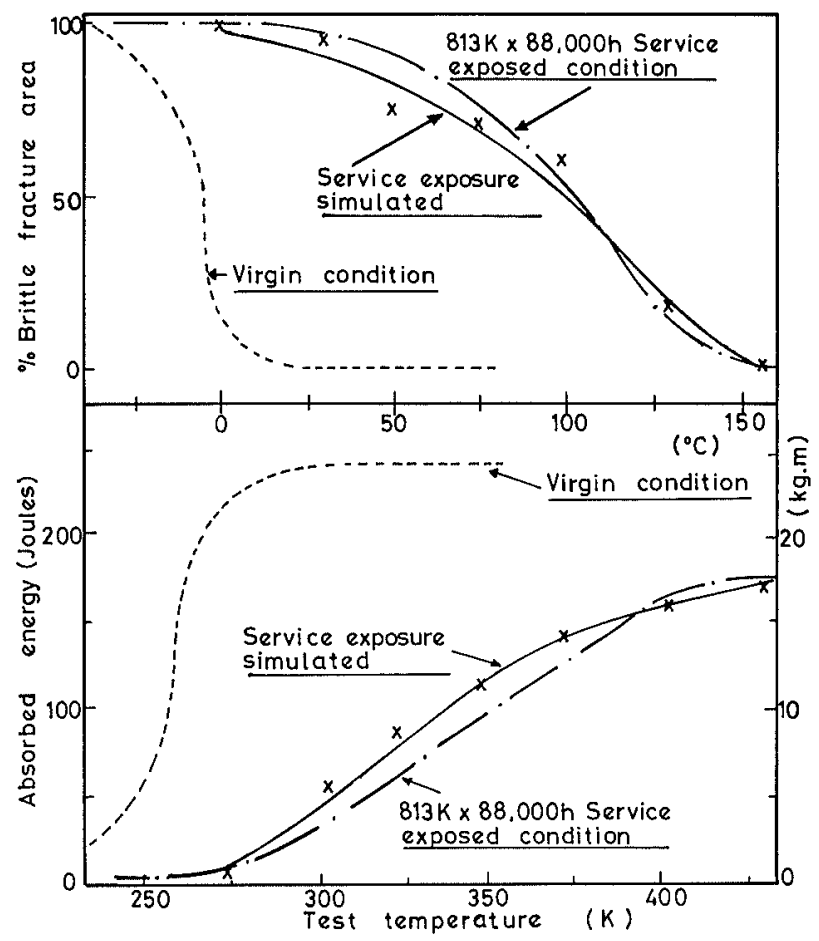

Fig. 10. Charpy impact test transition curves of Steel B in the service exposed state, "virgin" state and the service exposure simulated state.

Table 2. Chemical composition of Steel B. (wt \%) (after $813 \mathrm{~K} \times 88000 \mathrm{~h}$ service)

\begin{tabular}{ccccccccc}
\hline Material & $\mathrm{C}$ & $\mathrm{Si}$ & $\mathrm{Mn}$ & $\mathrm{P}$ & $\mathrm{S}$ & $\mathrm{Cr}$ & $\mathrm{Mo}$ \\
\hline Steel B (service exposed) & 0.12 & 0.31 & 0.51 & 0.020 & 0.009 & 2.31 & 0.98 \\
\hline
\end{tabular}


(a) As service exposed (813 $\mathrm{K} \times 88000 \mathrm{~h})$

(b) "Virgin" state

(c) Service exposure simulated

Fig. 11.

Comparison of typical carbide morphologies of Steel B in the service exposed, virgin and service exposure simulated states.
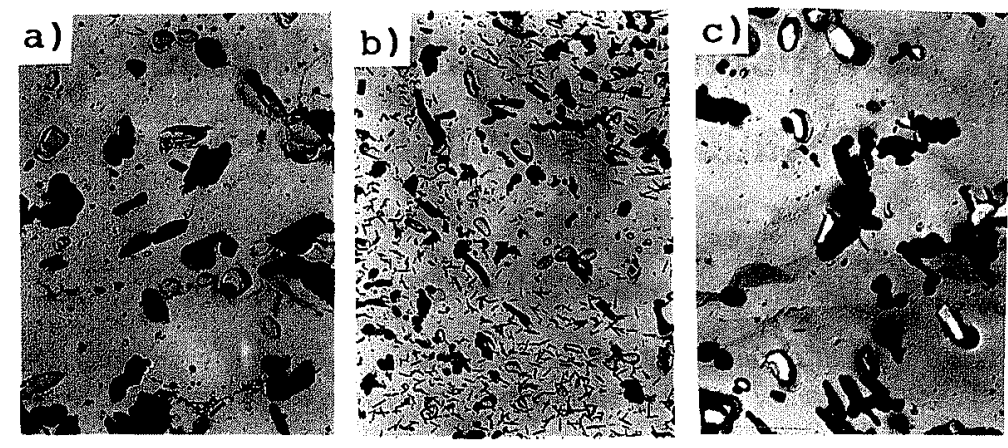

ness after the service simulation treatment $(145 \mathrm{Hv})$ was nearly equal to that after actual service (144 Hv). Fig. 11 compares the typical carbide morphologies in the service exposed state, "virgin" state and service exposure simulated state. It is clear that the simulation treatment is able to approximately reproduce the microstructural changes that occurred during actual service. Although a study of the tensile properties after simulation treatment was not carried out in this study, the hardness test results and the similarity of the microstructures in the service exposed and service simulated states suggest that, in addition to simulating the notch toughness, it may be possible to simulate the tensile properties after service as well by the above simulation treatment.

\section{Conclusions}

The long term embrittlement behaviour of a $2 \frac{1}{4} \mathrm{Cr}-$ 1 Mo steel with low impurity content was studied by isothermal aging for periods upto $10000 \mathrm{~h}$ at 813,873 and $898 \mathrm{~K}$. It was found that the embrittlement behaviour at the different temperatures could be expressed by the equation

$$
\Delta \mathrm{FATT}=A \cdot \mathcal{T}(\log t+8)+B
$$

where,

\section{$A, B:$ constants}

$T:$ the holding temperature $(\mathrm{K})$

$t$ : the holding time (h)

SFATT: the increase in the fracture appearance transition temperature.

It was also evident that G.E. Step cooling cannot be used to estimate the embrittlement caused by long term isothermal holding.

No grain boundary segregations of phosphorus or other impurity elements were detected, but dissociation of the initial bainitic microstructure and coarsening of carbides were observed to occur progressively as the holding time became longer, these reactions being faster at higher temperature. Measurement of carbide coarsening behaviour indicated that the increase in fracture appearance transition temperature could be related to the increase in mean carbide size.

It has been shown that by using the parameter $T(\log t+8)$ in the above mentioned equation, it is possible to formulate a method by which the hardness, microstructure and notch toughness of $2 \frac{1}{4} \mathrm{Gr}-$ 1 Mo steel after long term elevated temperature service of several years, can be effectively simulated in the laboratory by heat treatment of a few thousand hours.

\section{REFERENCES}

1) I. Masumoto, S. Wignarajah and Y. Okumura: Preprints of the National Meeting of Jpn. Weld. Soc., Japan Weld. Soc., Tokyo, (Autumn 1984), 166.

2) I. Masumoto, S. Wignarajah, Y. Okumura and M. Kutsuna: Proc. of the Indian Welding Conference IWC-87, Vol. 1, Indian Inst. of Weld., New Delhi, (1987), 531.

3) I. Masumoto, S. Wignarajah and H. Tsujimura: Trans. Jpn. Weld. Soc., 16 (1985), 89.

4) I. Masumoto, S. Wignarajah and T. Hara: Preprints of the National Meeting of Jpn. Weld. Soc., Japan. Weld. Soc., Tokyo, (Autumn 1987), 266.

5) T. Ogura, A. Makino and T. Masumoto: J.Jpn. Inst. Met., 45 (1981), 1093.

6) F. R. Larson and J. Miller: Trans. ASME, 74 (1952), 765.

7) K.W. Andrews, H. Hughes and D. J. Dyson: J. Iron Steel Inst., 210 (1972), 337.

8) K. Kinoshita and Y. Ihara: Nippon Kokan Tech. Rep., 62 (1973), 531.

9) F. Masuyama, K. Setoguchi, H. Haneda and F. Nanjo: Trans. ASME, J. Pressure Vessel Tech., 107 (1985), 260.

10) M. Shiga, R. Sasaki, S. Kirihara, F. Hataya, T. Shinoda and I. Aoki: J. Soc. Mater. Sci., Jpn., 33 (1984), 298.

11) K. Tamaki and J. Suzuki: Res. Rep. of Fac. of Engineering, Mie Univ., 7 (1982), 39. 